\title{
Comunicación y diversidad intercultural Conceptos, dispositivos y estrategias en red
}

\author{
Estrella Israel Garzón \\ (Universidad CEU-Cardenal Herrera de Valencia, España)
}

Recibido: 22/12/2010

Aceptado: 31/1/2011

\begin{abstract}
REsumen: Las formas actuales de interacción y mediación social a través de internet llevan a reconsiderar los conceptos de comunicación y de diversidad cultural. El paso de la diversidad cultural a la diversidad intercultural considera el desarrollo mediático como oportunidad para transformar las prácticas comunicativas. Los escenarios y los soportes del universo digital son útiles para repensar el periodismo desde conceptos como la representación de los diferentes, las nuevas temáticas, la posibilidad de dar voz a los sin voz, de desarrollar reportajes en profundidad -gracias a la multimedialidad o la hipertextualidad- y de desplegar estrategias de participación a partir de las modalidades del periodismo ciudadano, humanitario, de servicio, social e intercultural.
\end{abstract}

Palabras clave: Comunicación / intercultural / periodismo / diversidad cultural / internet

\section{Intercultural communication and diversity. Concepts, network devices and strategies}

Summary: Current forms of social interaction and mediation over the Internet transform the concepts of communication and cultural diversity. The passage of cultural diversity to incultural diversity considers media development as an opportunity to transform communication practices. The scenarios and supports of the digital universe are useful to rethink journalism in aim to a better representation of who's different, to open new issues, to give voice to the voiceless, to develop in-depth reports -through multimedia or hypertextand to deploy strategies of social participation from the modalities of citizen, humanitarian, service, social and intercultural journalism.

Key words: Communication / intercultural / journalism / cultural diversity / internet 
La única forma de preservar lo social es trasladarlo a la escala global.

\section{Zygmunt Bauman}

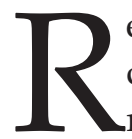
eflexionar sobre la comunicación y la diversidad cultural supone varias cuestiones al mismo tiempo: la definición de la identidad, el reconocimiento en términos de igualdad, el conocimiento de los otros, el diálogo entre las culturas, la integración social y la comunicación intercultural. Precisamente, en estos tiempos de globalización mediática, sociedades multiculturales, redes sociales, diversidad sociocultural, crisis económicas, movimientos y conflictos se plantea el objetivo intercultural en el sentido amplio del término, que no es más que el de articular mecanismos para un adecuado conocimiento del otro que se torne en reconocimiento recíproco, un conocimiento que comprende, de manera simultánea, educación y comunicación.

Si la educación intercultural es una necesidad de nuestros tiempos que se nutre de los valores humanos de igualdad, respeto, tolerancia, pluralismo, cooperación y corresponsabilidad social; del reconocimiento de los derechos personales, del reconocimiento positivo de las diversas culturas y lenguas, de la atención a la diversidad y del respeto a las diferencias, sin etiquetar ni definir a nadie; la posición intercultural comprende además una movilización activa contra toda manifestación de racismo o discrimina- ción a través de la superación de los prejuicios y estereotipos. En el ámbito comunicativo parece aún más urgente este objetivo para hacer realidad algunos principios vinculados con los derechos humanos, ya que "Todos los seres humanos nacen libres e iguales en dignidad y derechos y, dotados como están de razón y conciencia, deben comportarse fraternalmente los unos con los otros" (ONU 1948).

Otra referencia necesaria es la Declaración Universal sobre la Diversidad Cultural, cuya defensa es un imperativo ético indisociable del respeto de la dignidad humana, con especial incidencia en las personas que pertenecen a minorías y los de los pueblos autóctonos, donde se establece que

[...] el respeto a la diversidad de las culturas, la tolerancia, el diálogo, la cooperación, en un clima de confianza y de entendimiento mutuos están entre los mejores garantes de la paz y la seguridad internacionales. Los medios de comunicación pueden jugar un papel muy positivo para promover el respeto mutuo y combatir los estereotipos (Unesco 2001).

Desde hace décadas el concepto de diversidad cultural se estudia vinculado con la emergencia de la inmigración y la movilidad internacional, sociedades en movimiento y sociedades en conflicto, y también como terreno de denuncia de la desigualdad para abrir caminos para el diálogo, la convivencia y la pluralidad de opciones que se resumen en el concepto de 
diversidad intercultural. Entre el 2001 y el 2010 se han sucedido las citas internacionales que ponen el acento en la diversidad cultural, y así el 2008 se declaró año europeo del diálogo intercultural; el 2010 como año europeo contra la pobreza o la exclusión social y también como el año internacional del acercamiento de las culturas; el 2011 se presenta como año europeo del voluntariado. La profusión de fechas indica que todavía queda mucho por hacer en este terreno.

También hemos aprendido que la diversidad cultural no puede ser analizada con las mismas variables en unos espacios que en otros. En Latinoamérica, según el documento de la Asamblea General de la OEA (Medellín 2008), los colectivos que se encuentran en una situación de riesgo de exclusión social son los pueblos indígenas, afrodescendientes y comunidades minoritarias; mientras que en Europa ${ }^{1}$ las identidades más discriminadas desde la percepción pública lo son por el origen étnico, la religión, la tendencia sexual o la discapacidad. Sin embargo, las encuestas más recientes incorporan también la edad y la precariedad económica, vinculadas con la crisis como factores conducentes a nuevas discriminaciones.

\section{Diversidad cultural o diversidad intercultural}

Alejandro Grimson considera que la diversidad aparece a la vez como dificultad y condición de la comunicación. La dinámica de la interacción cotidiana se vincula a necesidades, intereses e incluso coyunturas, "[...] un campo de interlocución, como un conjunto de principios implícitos que los actores sociales incorporan como sentido común, algo compartido" (Grimson 2001: 53).

Por ello, lejos de las etiquetas, tan al uso en el márketing político, uno de los aspectos en los que hay que avanzar es en el paso de la diversidad cultural a la diversidad intercultural. Del mismo modo que la diversidad cultural es un diagnóstico de la variedad de culturas presentes a escala global; la diversidad intercultural es oportunidad para reflexionar y buscar los medios para que el diálogo intercultural y el diálogo entre los ciudadanos fortalezcan el respeto de la diversidad y traten la compleja realidad de nuestras sociedades y la coexistencia de distintas identidades culturales y creencias. Mientras que la diversidad cultural es yuxtaposición, la intercultural es comunicación entre culturas. La primera

1 En el informe "Discriminación en la Unión Europea 2008" respecto a las formas de discriminación que los ciudadanos de los 27 países perciben como muy o bastante extendidas, el primer lugar lo ocupa el origen étnico con un 62 por ciento, le sigue la orientación sexual con un 51 por ciento, la discapacidad con un 45 por ciento; la edad y la religión o creencias con un 42 por ciento, y finalmente el género, a escala europea, con un 36 por ciento. Los porcentajes varían en función de los países. 
es convivencia, la segunda, intercambio; la cultural remite al conocimiento; mientras que la intercultural es reconocimiento recíproco; la diversidad cultural se refleja en manifestaciones cuando somos observadores -espectadores- del comportamiento de otros, los miramos; mientras que el sentido intercultural busca la correspondencia en las miradas. Finalmente, en el primer rango se pone el acento en la visibilidad, mientras que en el segundo se busca la profundización. El hecho de que una sociedad o un espacio geográfico sea multicultural no garantiza que en él se viva la interculturalidad. Al contrario, esta diversidad presagia todo tipo de conflictos.

El concepto intercultural no es monolítico, sino dinámico y se refleja en la pluralidad de ámbitos en los que se puede aplicar el internacional, el interétnico, el interreligioso y el intercultural en sentido amplio que se vincula con el concepto de diversidad e implica diferencia respecto a un modelo que pretende imponerse desde el punto de vista social o cultural. La diversidad intercultural incorpora las variables socioculturales desde un planteamiento flexible y evolutivo; por ejemplo, conviven discriminaciones por razón de género, clase social, discapacidad, tendencia sexual, dimensión étnica, dimensión religiosa, por enfermedad, por el origen, por la edad o por la apariencia física.

Entre los argumentos favorables a la diversidad intercultural podemos desgranar uno de carácter intrínseco, ya que la pluralidad es enriquecedora; un argumento identitario, que favorece los valores culturales inherentes; un argumento democrático, en el sentido de la igualdad de oportunidades; un argumento social, desde el punto de vista de la integración y la solidaridad $y$, finalmente, un argumento de la no discriminación. La apuesta intercultural considera a todos los otros y no debe confundir la apariencia -ni el márketing turístico- con "la cultura" como identidad. Este desplazamiento de la diversidad cultural a la intercultural requiere de una consideración del concepto de cultura en profundidad, no simplemente como un iceberg, ya que no podemos hacer de la interculturalidad un eslogan y conformarnos con las apariencias que resultan engañosas. Por ello se habla del iceberg de las culturas, es decir lo que vemos como manifestaciones visibles: gastronomía, entorno, lenguaje, costumbres, rituales, comportamientos, indumentarias, frente a lo que se queda en el fondo y no percibimos como la atribución de roles, tradiciones, actitudes, estatus, valores, creencias o nivel de socialización.

Trabajar para la interculturalidad, la educación y la comunicación intercultural implica tanto a las instituciones públicas, con políticas de integración, como a los medios y los profesionales de la comunicación con principios éticos, contrarios a la discriminación, con la incorporación de buenas prácticas; además, necesita de 
las organizaciones sociales y de ciudadanías activas para la movilización y la denuncia.

\section{Imágenes del mundo y redes sociales en la escala global}

Las imágenes del mundo que consumimos dentro de la agenda mediática están marcando nuestra percepción de lo que sucede tanto en entornos próximos como lejanos, así como respecto a los temas sobre los que hay que reflexionar. Podemos hablar de diferencia tanto en el ámbito global, que muestra realidades desiguales, como en el ámbito comunicativo, con representaciones $u$ omisiones que deforman u ocultan determinadas realidades; por ejemplo, el diagnóstico de países pobres y países ricos, de injusticia social, de desfase norte-sur, del cuarto mundo en el primer mundo, así como otras formas de discriminación cultural que se hacen visibles en comportamientos cotidianos y en estrategias desinformativas más amplias.
Pensemos en los objetivos del Milenio $^{2}$ para combatir la pobreza, el hambre, la enseñanza no universal, la desigualdad entre géneros, la mortalidad materno-infantil, el VIH-Sida, el paludismo y otras enfermedades, la falta de sostenibilidad del medio ambiente, la ausencia de desarrollo, unidos a catástrofes naturales y obtendremos una primera relación de grandes problemas sobre los que hay que trabajar desde la escala global a partir de una dimensión social e intercultural.

Los procesos migratorios, en ocasiones voluntarios, pero en la mayoría de los casos forzados por razones económicas, étnicas, políticas, medioambientales o provocadas por catástrofes naturales, así como la ausencia de desarrollo en buena parte del mundo y las crisis económicas desembocan en el hecho de que el lugar de nacimiento no es el lugar de residencia; ${ }^{3}$ esto ocurre en sociedades cada vez más diversas. La globalización comunicativa también tiene dos: fenómenos interrelacionados uno que denominamos

2 Los Objetivos de Desarrollo del Milenio de Naciones Unidas constan de ocho puntos clave y tienen unas metas muy concretas:

Objetivo 1: Erradicar la pobreza extrema y el hambre.

Objetivo 2: Lograr la enseñanza primaria universal.

Objetivo 3: Promover la igualdad entre géneros y la autonomía de la mujer.

Objetivo 4: Reducir la mortalidad infantil

Objetivo 5: Mejorar la salud materna.

Objetivo 6: Combatir el VIH/Sida, el paludismo y otras enfermedades.

Objetivo 7: Garantizar la sostenibilidad del medio ambiente, y

Objetivo 8: Fomentar una asociación mundial para el desarrollo.

3 Las imágenes públicas de estos movimientos migratorios están llenas de dramas. 
el "márketing global", y, en íntima relación con esta, la cultura popular internacional -un universo de popularidad, ${ }^{4}$ efímera en muchos casos- que alimenta tanto los autoestereotipos como los heteroestereotipos.

Continuamente nos tenemos que preguntar sobre la frontera que separa lo importante de lo interesante; un paseo por la jerarquización de noticias nos sugiere que las aspiraciones respecto al pluralismo no están tan amplificadas, sino que la anécdota, el impacto, la trivialidad o la mercantilización condicionan los mensajes.

De hecho, las tendencias prevalentes siguen siendo la visualización de los dramas personales, las noticias programadas, la transnacionalización de la información y la patentización de las privacidades -cuando no de intimidades- en sociedades sacudidas por los conflictos o la crisis económica y por el poder creciente de los nuevos medios.

Otro factor para confrontar la diversidad de las culturas se encuentra en el elemento de la sociedad global que ha transformado los modos de interacción social, el mercado, las voces de la sociedad, la distribución del poder y los modos de producción, incluidas las nuevas propagandas.
El carácter transformador, de acuerdo con Echevarría, trasciende lo que llamamos internet y comprende

[...] un sistema tecnológico que incluye las redes telemáticas, la telefonía móvil, la imagen y el sonido digital (televisión, radio, fotografía, video, cine digitalizado..) videojuegos, simulaciones, realidad virtual $[\ldots]$ (Echevarría 2009: 560).

La globalización y la sociedad-red plantean interrogantes respecto a la distribución de los bienes digitales cuando un total de 20 países concentran más del 75 por ciento de los usuarios. Sobre un mercado total de 1.733 millones de usuarios, al top 20 le corresponden 1.325 millones. Entre los cinco con mayor incidencia destacan en los primeros puestos China (20,8 por ciento), Estados Unidos (13,1 por ciento), Japón (5,5 por ciento), India (4,7 por ciento) y Brasil (3,9 por ciento).

Sin embargo, cualquier cifra o estadística de desarrollo de internet ha de ser puesta en relación con los criterios poblacionales, de manera que se produce el denominado "efecto horquilla", ya que un bajo nivel de desarrollo en países con gran densidad de población, presagia una curva ascendente. La evolución en el número de usuarios en la primera década del siglo XXI es espectacular.

4 Los famosos globales procedentes del mundo del deporte, del universo musical, del cine, de la televisión o de la moda vinculados con el concepto de fads (modas efímeras). 


\section{Gráfico 1}

\section{Usuarios de internet en el mundo}

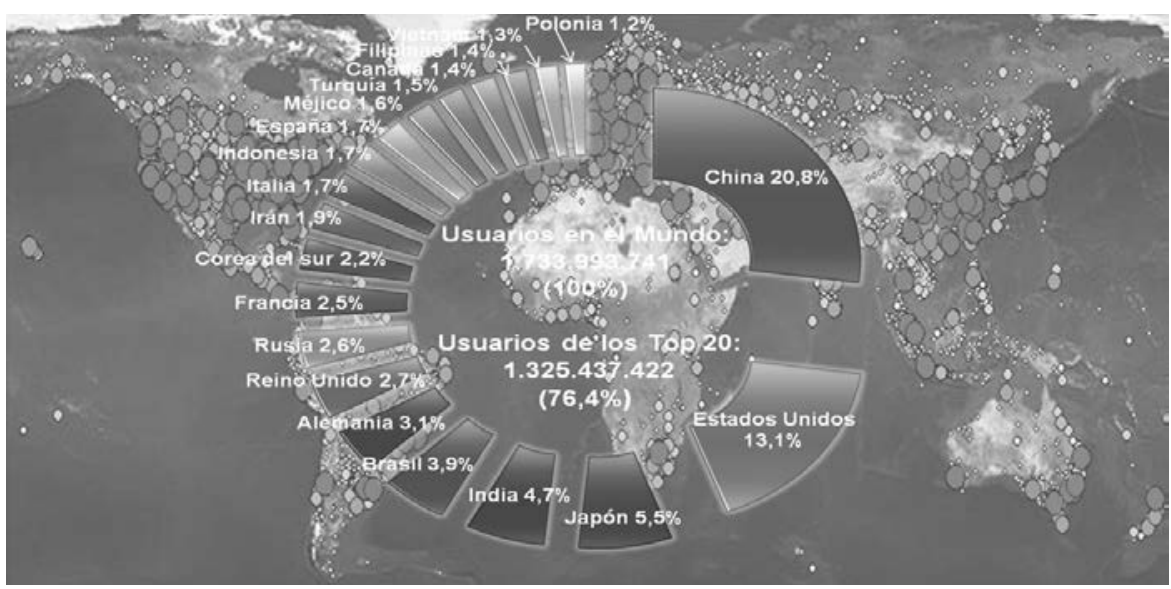

Fuente: Internet World Stats, septiembre del 2009. Elaboración propia.

\section{Gráfico 2}

\section{Usuarios de internet por regiones}

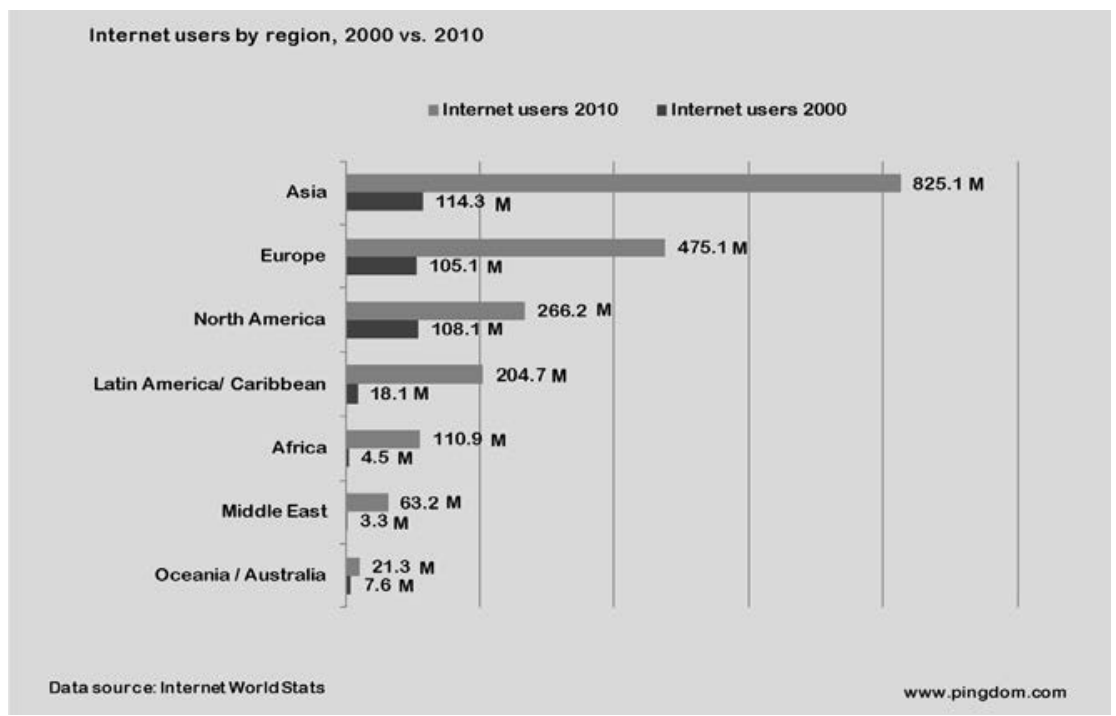

Fuente: Internet World Stats.

Elaboración propia. 
Una mirada continental nos indica que los países de América Latina y El Caribe contaban en el año 2000 con algo más de 18 millones de usuarios y que en el 2010 superan los 204,7 millones de usuarios.

Para analizar la penetración de internet hay que considerar los indicadores poblacionales encabezados por Brasil, México, Colombia Argentina y Perú.
También las cifras respecto al número total de usuarios mantiene los primeros puestos poblacionales: Brasil, México, Argentina, Colombia, Venezuela, Chile y Perú. ${ }^{5}$

Sin embargo, cuando analizamos el porcentaje de penetración de internet en la población apreciamos que Argentina (64,4 por ciento), Uruguay ( 52,8 por ciento), Chile (50 por ciento), Colombia (48,7 por ciento) y Costa Rica (44,3 por ciento) son los países con mayor implantación en la red.

\section{Gráfico 3}

Población de países latinoamericanos

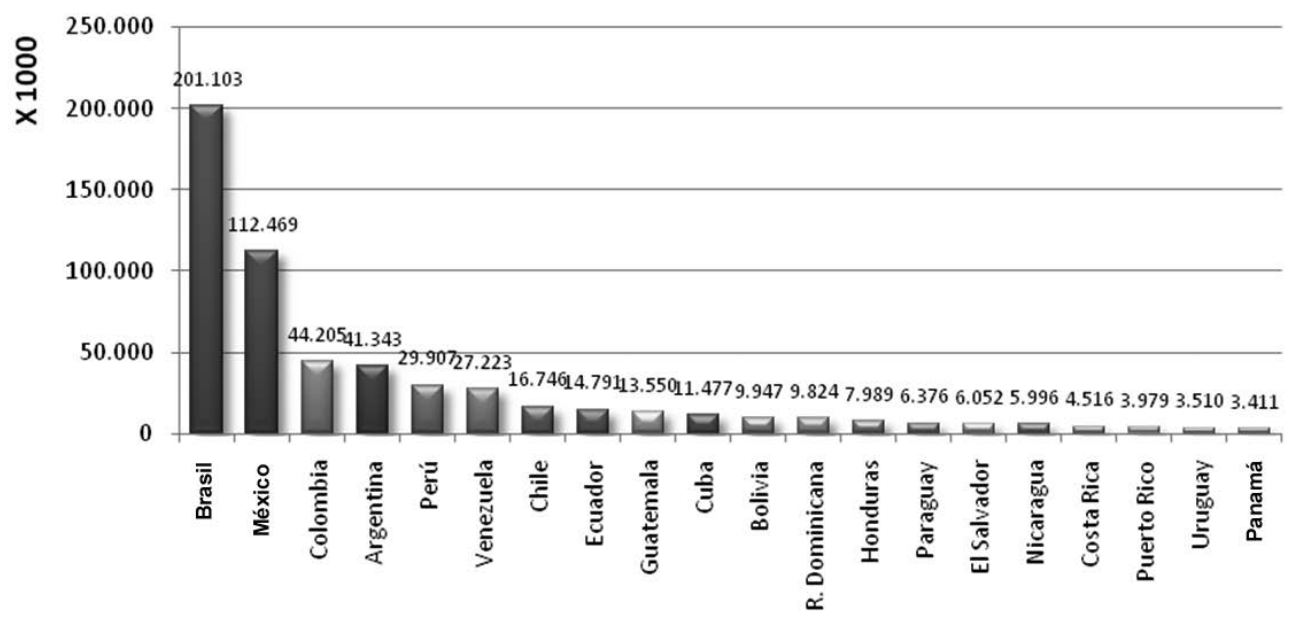

Fuente: Internet World Stats, junio del 2010.

5 La población total de América Latina es de 574.416.368 habitantes, de los cuales 200.144.290 son usuarios de internet, de manera que la media continental se sitúa en un $34,8 \%$ de penetración (Internet World Stats, junio del 2010). 
Gráfico 4

Usuarios de internet en latinoamérica

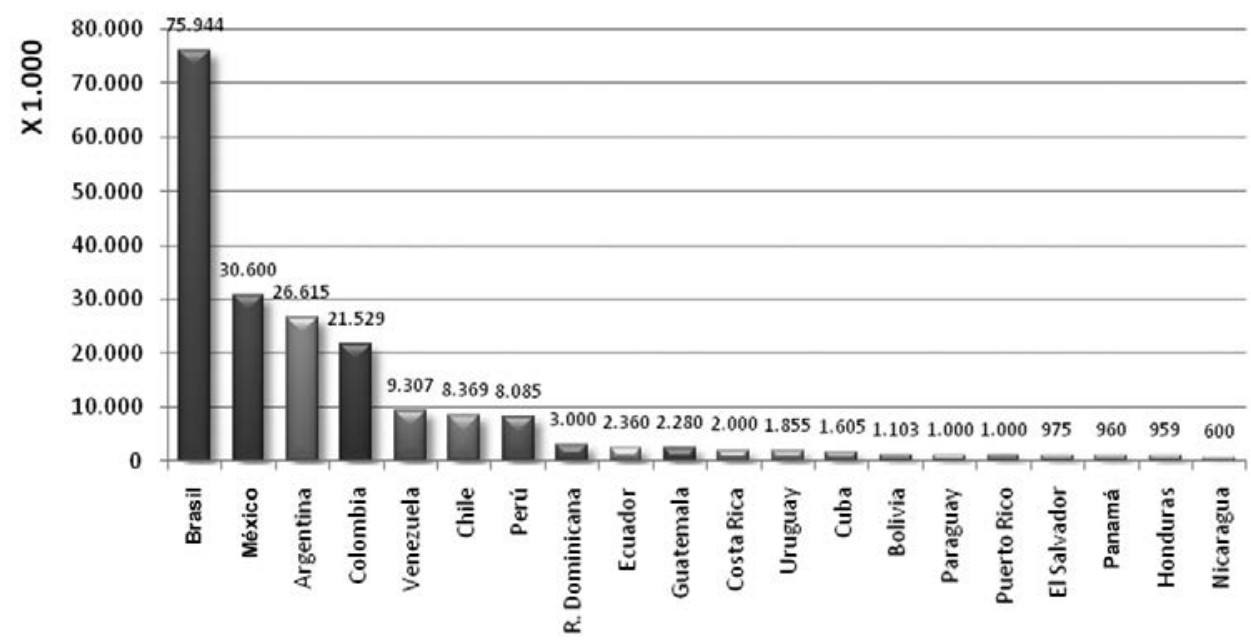

Fuente: Internet World Stats, junio 2010.

Gráfico 5

Penetración de internet en la población

(porcentaje)

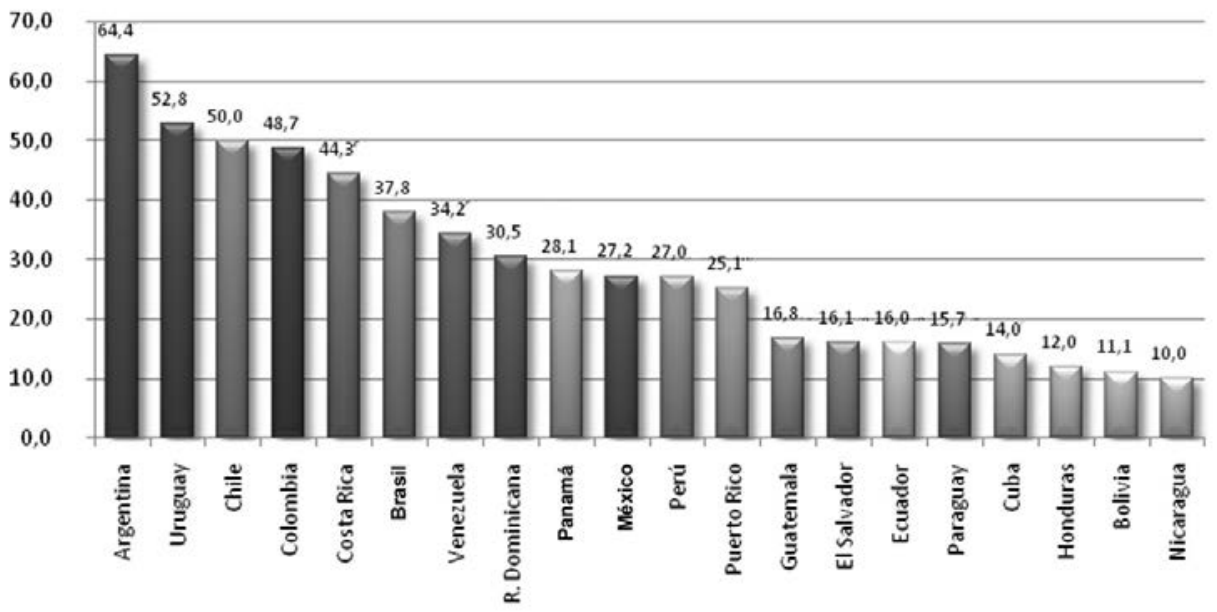

Fuente: Internet World Stats, junio del 2010. 
Tampoco podemos olvidar que el combate por la libertad de expresión se traslada hoy a la blogosfera. ${ }^{6}$

El universo digital abre posibilidades para la movilización social, a través de ciudadanías activas, estrategias y redes sociales. Los movimientos sociales usan internet como canal de comunicación tanto para promover la relación entre sus miembros como para alentar acciones de protesta. El carácter democrático y participativo del sistema conecta con las aspiraciones de la mayoría de los ciudadanos. También hay rasgos comunes entre estos movimientos y la red, son interac-

\section{Principales países que violan la libertad de expresión en la web}

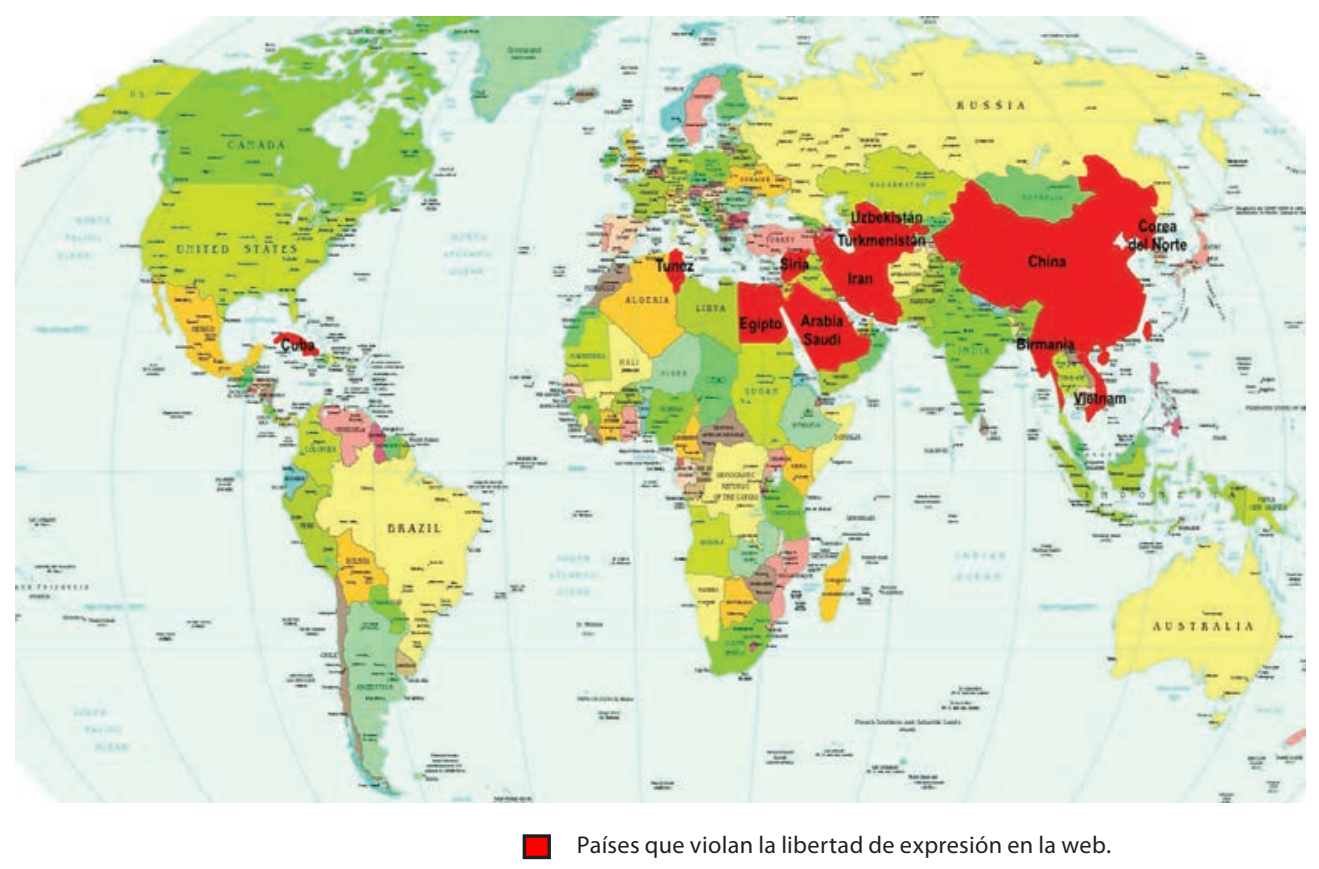

Fuente: Reporteros sin Fronteras, 11 de marzo del 2010.

6 Hay 119 ciberdisidentes encarcelados, principalmente en China, Vietnam, Irán, Cuba o Siria; también se juzgan en Egipto y Turquía. La lista de los "Enemigos de Internet" establecida por Reporteros sin Fronteras ha reunido en el 2010 a los principales países que violan la libertad de expresión en la web: Arabia Saudí, Birmania, China, Corea del Norte, Cuba, Egipto, Irán, Uzbekistán, Siria, Túnez, Turkmenistán y Vietnam (Lucie Morillon, responsable de Nuevos Medios de Comunicación, y Jean-François Julliard, secretario general de RSF). 
tivos y bidireccionales, horizontales, autónomos, globales, movilizadores y difusores de culturas alternativas.

De todos modos, se encuentran usos contradictorios, de manera que las redes sociales pueden ser utilizadas por grupos antidemocráticos que promueven estrategias del odio, pero también por movimientos que defienden el pacifismo, la ecología y los derechos humanos. Las posibilidades de los usuarios de intervenir se multiplican, la información está abierta a la evaluación, la jerarquización, los enlaces, el comentario, la respuesta, la entrevista, la cooperación, la conversación, el voto y la adición de otros contenidos.

\section{Conceptos y dispositivos periodísticos para la interculturalidad}

Para promover una comunicación intercultural desde el ámbito del periodismo, debemos procesar las informaciones a partir de los detectores de ruidos interculturales. El primer detector es el de la asociación temática para determinar con qué temas se asocia a los grupos minoritarios; si lo son principalmente en el ámbito de la desviación y la negatividad-violencia, crimen, drogas, robos, prostitución, relaciones culturales, o estadísticas vinculadas con la delincuencia- o bien se sitúan en otras esferas más positivas, como la integración o las manifestaciones culturales propias. Vincular a los "diferentes" con conflictos y com- portamientos negativos o asociales pone, en ocasiones, al descubierto determinados prejuicios larvados en la sociedad.

El segundo, quizá el más conocido, es el de la nominación, si se nombra al grupo, si se generaliza la identidad, dentro de las prácticas del etiquetaje. Ese "nombrar al otro" de un modo distorsionador se produce cuando se hace una mención explícita a la pertenencia étnica, al país de origen, al color de su piel, a su identidad y ello no es necesario para la comprensión del acontecimiento. Un ejemplo representativo es la orden de desmantelamiento de los campamentos ilícitos dictada en Francia en el verano de 2010 en la que se hace mención expresa a los Rom (gitanos) (gráfico 7).

Un tercer indicador se sitúa en la utilización de expresiones populares, recursos léxicos o comparaciones que negativizan al diferente. Al igual que en la argumentación y los editoriales, las distorsiones aparecen también cuando se establece una divisoria entre nosotros y ellos. Para mejorar el tratamiento informativo, hay que pluralizar las fuentes; en numerosas ocasiones los hechos vinculados a los diferentes se nutren de fuentes institucionales (fuentes policiales, gubernamentales y de la administración de justicia) y al mismo tiempo los diferentes tienen una menor presencia, sea por falta de medios económicos o por el filtro de marginación, al considerarlos poco legitimados. 


\section{Gráfico 7}

Facsímil de la orden de desmantelamiento de los campamentos gitanos en Francia

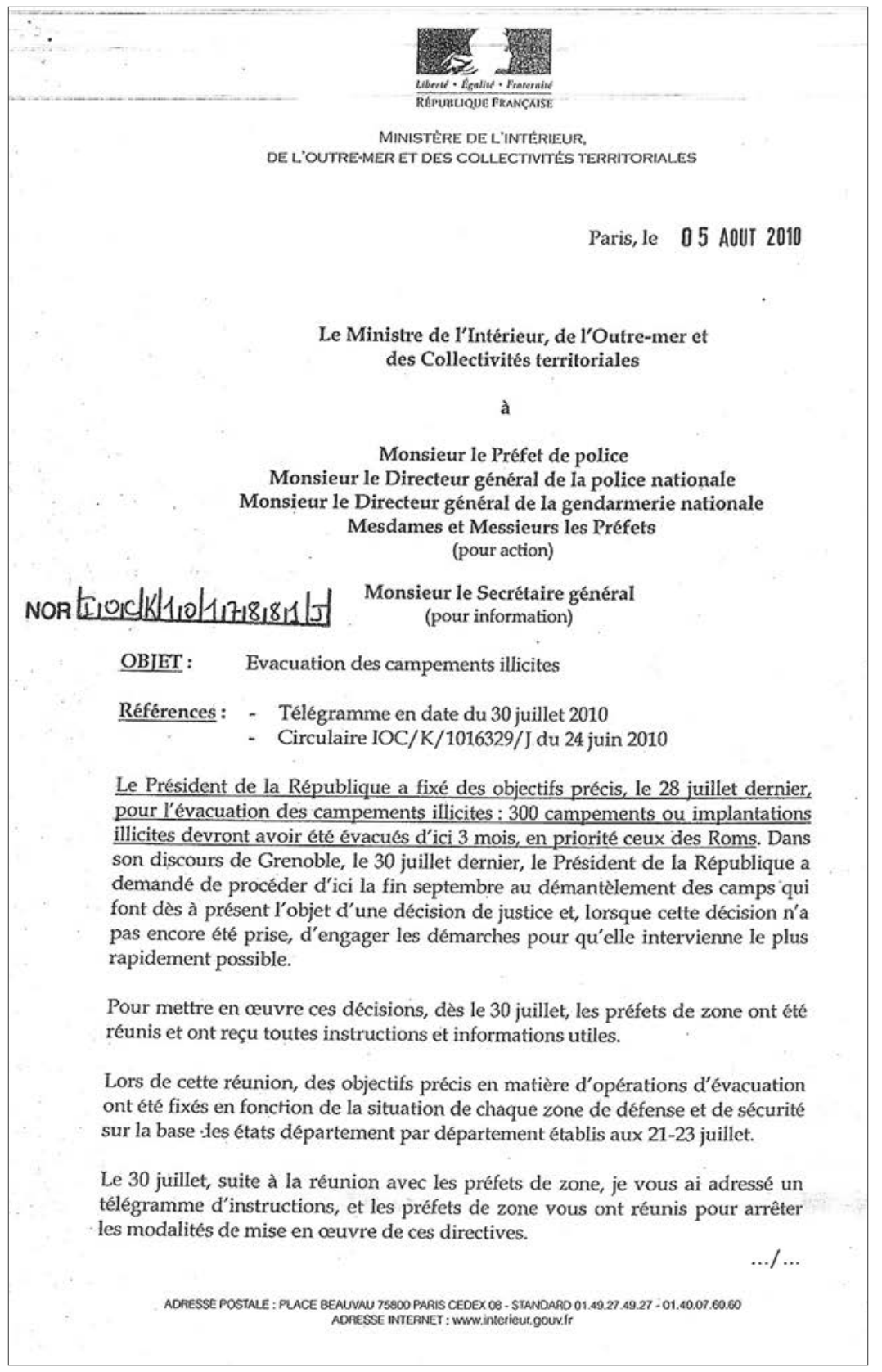


Gráfico 8

Primera plana de un diario peruano que incluye una referencia racial

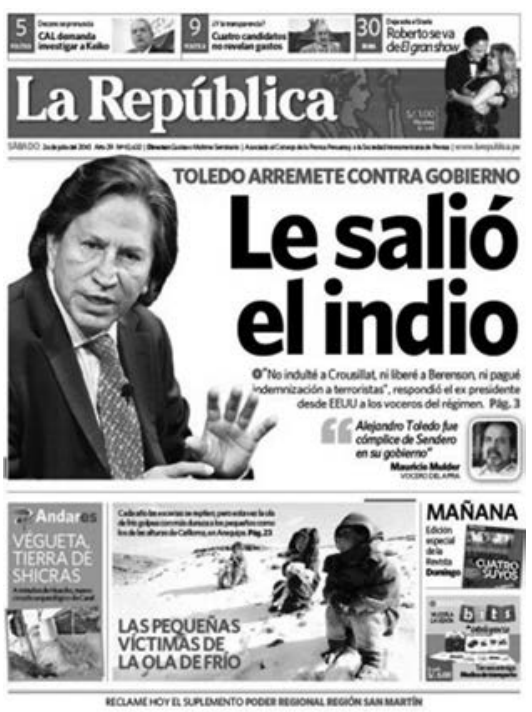

También los movimientos sociales y colectivos ciudadanos, que denominamos "voces de la sociedad", pueden establecer sugerencias y recomendaciones para un tratamiento más preciso y socialmente responsable. Un buen ejemplo son los documentos y guías establecidas por las organizaciones no gubernamentales sobre el sida ${ }^{7}$ o por las familias de enfermos mentales. ${ }^{8}$ A la hora de desarrollar buenas prácticas con frecuencia se realiza un llamamiento a los responsables y a los trabajadores de los medios de comunicación para que afronten el reto de la complejidad de manera adecuada, sin recurrir a la trivialidad o a la banalización. De hecho, los medios de comunicación actúan como soportes de comunicación y, al mismo tiempo, son instrumentos de interconexión en las sociedades. ${ }^{9}$

Para comprobar la calidad intercultural de una información periodística hay que plantearse una serie de

7 La Coordinadora Estatal de VIH-Sida (Cesida) realizaba un llamamiento:

- al profesionalismo, siendo vigilante ante una infección que afecta seriamente a la sociedad y la vida de muchas personas;

- a la responsabilidad, actuando para la prevención de la enfermedad con una atención especial a las medidas, sin trivializar;

- a la dignidad, con el fin de no atentar contra la imagen de las personas que viven con el SIDA;

- y finalmente a la humanidad, con solidaridad hacia todas las personas enfermas. Ya que es necesario tomar conciencia que para transmitir información científica con rigor, es necesaria también una sólida base pedagógica que ayude a incluir, sin provocar falsas expectativas o creencias engañosas (Cesida 2006: 26).

8 La Confederación Española de Familiares de Enfermos Mentales (Feafes) establece una complicidad constructiva entre el colectivo afectado y los medios de comunicación, para que a partir del conocimiento y la aceptación de las dos entidades se pueda extender en la sociedad un compromiso mutuo y un trabajo conjunto (Feafes 2003).

9 El Colegio de Periodistas de Cataluña ha actualizado en el 2010 el Manual de estilo para el tratamiento de las minorías étnicas en los medios de comunicación de 1996 y se ha presentado con una nueva denominación: Guía sobre el tratamiento de la diversidad cultural en los 
cuestiones. ${ }^{10}$ La primera es saber si el propio periodista tiene conciencia de sus prejuicios personales respecto a los desafíos, los acontecimientos y las personas de los cuales informa. Esta pregunta puede extenderse a su consideración acerca del poder de las imágenes o las palabras. Conviene, posteriormente, preguntarse sobre la necesidad de indicar o no el grupo étnico de las personas mencionadas y si se emplea un lenguaje correcto. También es necesario saber si las personas entrevistadas están relacionadas con la información o si se eligieron porque atraerán la atención del telespectador. Asimismo, hay que comprobar si los representantes de las minorías y los testigos que figuran en un reportaje son mencionados por razones válidas. Las consecuencias que puede tener el reportaje sobre las opiniones de los telespectadores y sobre la vida de las personas que se mencionan no son anodinas.

\section{Modalidades y estrategias en red}

Con las premisas de que no hay modelos culturales superiores o inferiores y de que cuando hablamos de diversidad intercultural nos estamos refirien- do a relaciones entre personas, ningún contenido queda fuera siempre que se mueva por un fin: el de ser socialmente positivo, que podría responder al principio de que "Está prohibida la indiferencia frente al sufrimiento del otro". Las diversas modalidades periodísticas que se han proyectado en red hacia la sociedad tienen elementos de periodismo cívico, solidario, de servicio, participativo, social e intercultural. Estos son solo algunos de los apelativos que caracterizan esta nueva etapa y que se combinan con otros modelos tradicionales como el periodismo de denuncia, de investigación, de precisión; todos ellos tienen un rasgo común: la conciencia de que al otro lado hay unos ciudadanos a los que se puede hacer saber -informar- sobre los acontecimientos pero también sobre injusticias, corrupción, mentiras, intereses, situaciones discriminatorias... El respeto a la dignidad de "todos los otros" puede amplificarse. También se están produciendo cambios en los perfiles profesionales, hemos pasado del gatekeeper y el newmaking hacia modelos profesionales inseparables de la red como periodista polivalente, multimedia, editor de contenidos e incluso social media manager, aunque esta última denominación

en los medios de comunicación. Otros recurrsos útiles para buenas prácticas se pueden en-

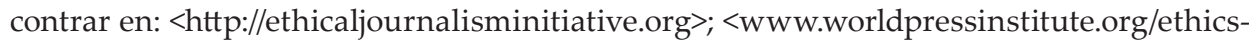
links.htm\#jcodes $>$ o <www.coe.int/t/DG4/ANTI-DISCRIMINATION-CAMPAIGN/>.

10 Las preguntas se pueden consultar en CCJ: $<\mathrm{http}: / / \mathrm{ww} w$. concernedjournalists.org/diversity-checklist>. 
está más cerca del márketing que de la información periodística en sentido estricto.

Para expresar adecuadamente la diversidad intercultural, en primer lugar podemos recurrir a algunas técnicas del periodismo cívico que busca cerrar la brecha abierta entre los medios y sus audiencias, y ampliar la agenda que deja de ser eminentemente político-gubernamental para incluir temas que interesan a la ciudadanía. ¿Cuáles son los temas que interesan a la comunidad? Además de las encuestas sociológicas es posible organizar dinámicas de grupo o procedimientos cualitativos menos estructurados como las reuniones públicas, las conversaciones y entrevistas abiertas. En este sentido, es interesante recordar la experiencia del Charlotte Observer ${ }^{11}$ (Carolina del Norte) en el periodo 1994-1996 para denunciar la situación de los barrios pobres de la ciudad de Charlotte.

Entre las herramientas utilizadas, los sitios web, el correo electrónico, las encuestas, los foros on line, los canales de charlas, los blogs, las bitácoras permiten, como actividades características, establecer preconceptos o estereotipos sobre la comunidad; identificar a las personas catalizadoras de un grupo y a los conectores entre grupos di-

\section{Gráfico 9}

Denuncia sobre la pobreza

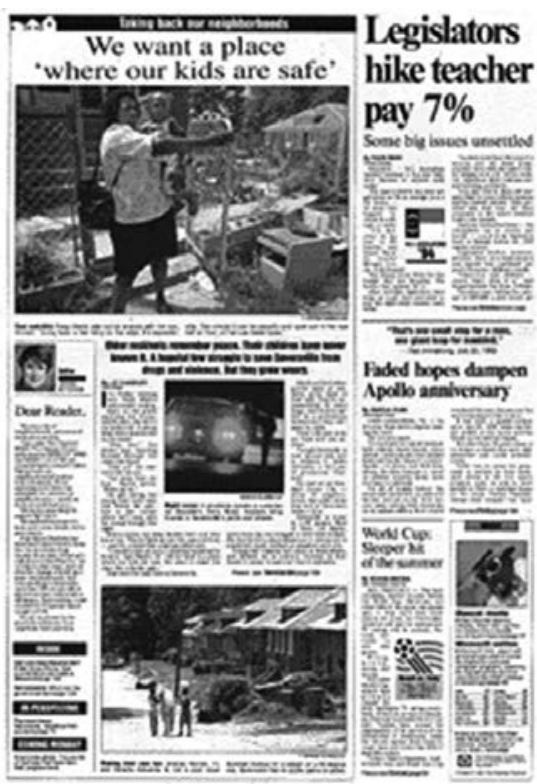

ferentes de la comunidad; determinar los lugares donde los residentes tratan informalmente los temas comunitarios; entrevistas abiertas a través de conversaciones; el contraste entre los preconceptos y las opiniones expresadas y el desarrollo de temas y artículos. También se establecieron en esa experiencia alianzas con medios locales, (prensa digital, radio y televisión), organizaciones ciudadanas, universidades, institutos de investigación, organismos públicos, etcétera.

11 "[...] public journalism is about putting a new lens on our camera. It's putting a widerangle lens on what we do...so we can begin to see something more than we have been seeing" (Buckner 13 de setiembre de 1995). Véase Glasser, Theodor L. (ed.) (1999). The idea of public journalism. Nueva York: The Guilford Press. 
Otro factor transformador se sitúa en el escenario humanitario, que se ha modificado sustancialmente desde la década de 1990, con un notable incremento de organizaciones sociales para la cooperación y un aumento significativo de agencias humanitarias. Los periodistas deben adaptarse al trabajo de las organizaciones no gubernamentales, como estas a las peculiaridades de los medios de comunicación. Las propias organizaciones se configuran como plataformas comunicativas. Según Ivan Pino (en línea), los valores 2.0 se corresponden con los de las ONG: naturaleza asociativa, finalidad social, software libre, gestión democrática, participación abierta. El nuevo ecosistema de la comunicación 2.0 está cambiando los mensajes, llega mucho más el mensaje de las experiencias, menos estadísticas y más relatos de cooperantes en el terreno. ${ }^{12}$

Ushahidi propone un nuevo paradigma en la labor humanitaria. El viejo paradigma consiste en que "uno trabaja para muchos"; los periodistas y cooperantes extranjeros llegaban en avión, informaban sobre el desastre y repartían ayuda con la información que tengan. El nuevo paradigma consiste en que "muchos trabajan para muchos": las víctimas proporcionan datos sobre el terreno; una multitud autoor-
Gráfico 10

Periodismo en la web

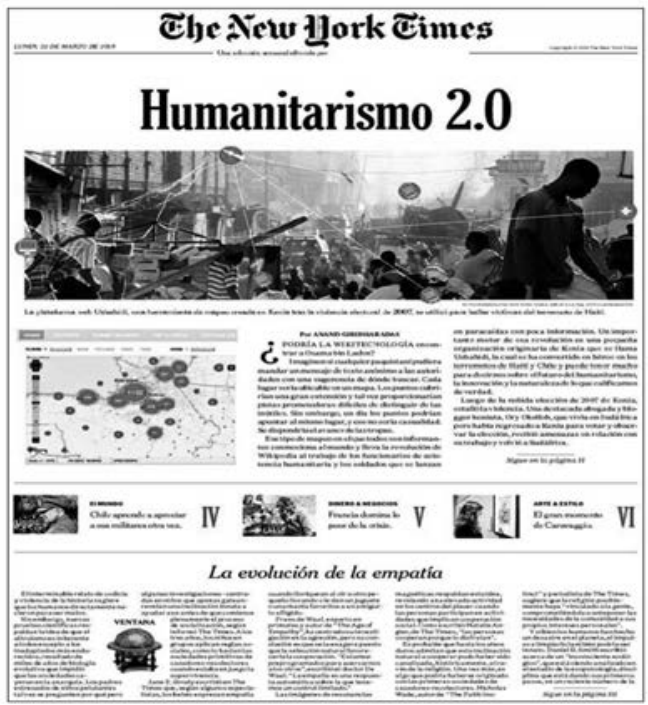

ganizada de voluntarios traduce SMS y contribuye a repartir la ayuda: los periodistas y cooperantes se orientan a partir de estos datos. También es una nueva frontera de la innovación, basa su funcionamiento en los móviles, con un programa de código abierto. Con cada nueva aplicación se transforma el concepto de dar testimonio de una tragedia. En la era de la instantaneidad este tipo de testimonios nos pone delante de un hecho más inmediato: el de las verdades colectivas y suficientemente fiables (Giridharadas 25 marzo del 2010: 1 y 4).

12 La recuperación de la confianza de la ciudadanía hacia los medios no será posible sin una nueva alianza entre periodistas y organizaciones sociales, que parta de la autocrítica y de la reubicación de los dos colectivos en un nuevo paradigma comunicativo (Murciano, en línea). 
Las sociedades y los individuos están cada vez más interconectados, pero simultáneamente más vulnerables, también pueden encontrar respuestas en el periodismo de servicio o de advertencia, el que tiene el potencial de alertar a la comunidad de los problemas antes de que sucedan, de que lleguen a ser acontecimiento. Es un periodismo que da lo relevante y útil para la vida de sus destinatarios. Con informaciones de localización, de identificación y de acción o táctica pone a disposición modelos de conducta explícitos o implícitos. En la interacción de comunicación y riesgo, contenidos de promoción de la salud, de alertas medioambientales o de seguridad entran en este segmento que recupera la noción de servicio público.

Además de los nuevos temas, del servicio a la sociedad, la condición y posición de los receptores se transforma en actores comunicativos con referencias al periodismo participativo, ciudadano, de fuente abierta, de manera que en el periodismo 3.0, “[...] los medios sociales se definen por la convergencia de individuos en redes sociales, el uso de los nuevos medios y la sindicación o enlaces de ideas, escritos y otros contenidos informativos y de opinión" (Varela 2005: 77-163). Hoy se habla de periodismo participativo porque el desarrollo tecnológico amplía las posibilidades de participación social. Frente al esquema unidireccional de los medios tradicionales con una estructura de propiedad definida y una determinada línea editorial, las nuevas tecnologías permiten un modelo bidireccional y poliédrico ya que la transmisión en red relaciona personas absolutamente deslocalizadas, la situación espacial es ahora irrelevante ya que emisores y receptores están intercomunicados. Este potencial se traduce en la idea de que cada recep-

Gráfico 11

Promoción de la salud y alerta medioambiental
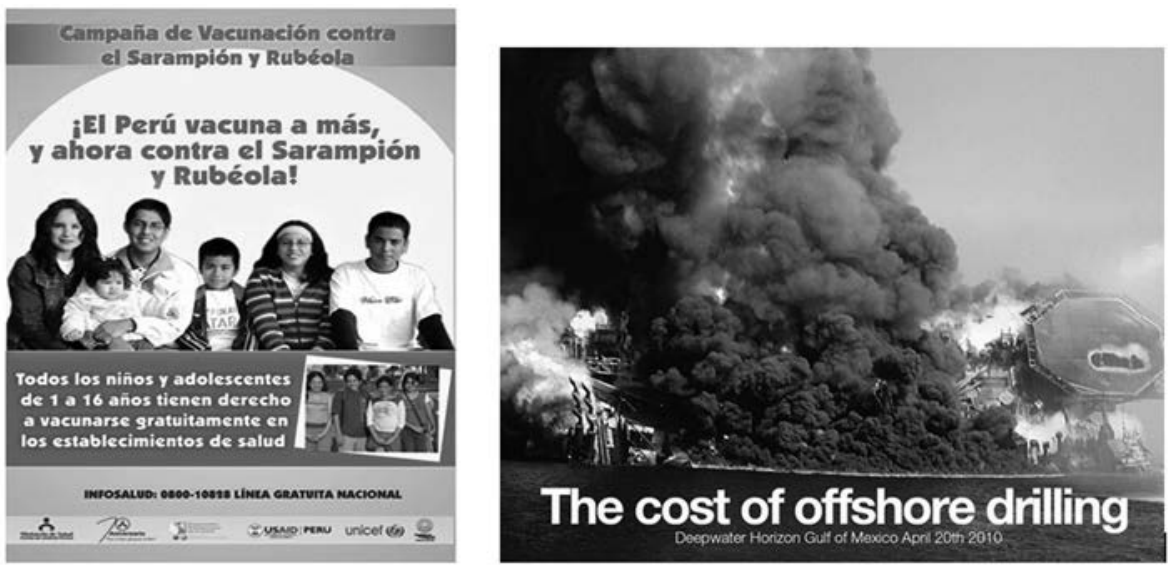
tor o usuario de la red se convierte en un transmisor. Blogs, redes sociales y cualquier forma de expresión en red pueden ser significativos en el universo digital para procurar una adecuada representación de la diversidad e incluso para la movilización cuando la mediación es distorsionadora, inadecuada o discriminadora.

Finalmente, llega el momento del periodismo social. Este es un periodismo que asume su protagonismo y su responsabilidad en los procesos sociales. Su objetivo principal es que la comunicación sirva para generar un mejor diálogo entre los actores de la sociedad. El periodismo social busca dar una visión más amplia que ayude a la construcción de una sociedad más inclusiva.
En la convergencia entre los medios y la red, los dispositivos profesionales tienen la potencialidad de transformar las prácticas dominantes: a través de textos alternativos para no discriminar; de buscar los contextos con reportajes en profundidad e información de servicio gracias a la hipertextualidad, la multimedialidad y la interactividad; denunciar mediante historias de vida; diversificar las fuentes y las voces y asumir el papel de mediador en la búsqueda de soluciones. Hacer un esfuerzo para encontrar nuevas fuentes de información y cuestionar el discurso clásico puede servir a veces para evitar los estereotipos.

Una buena práctica requiere que la información no se deslice hacia la publicidad y que en contextos intercultu-

\section{Gráfico 12}

Periodismo participativo

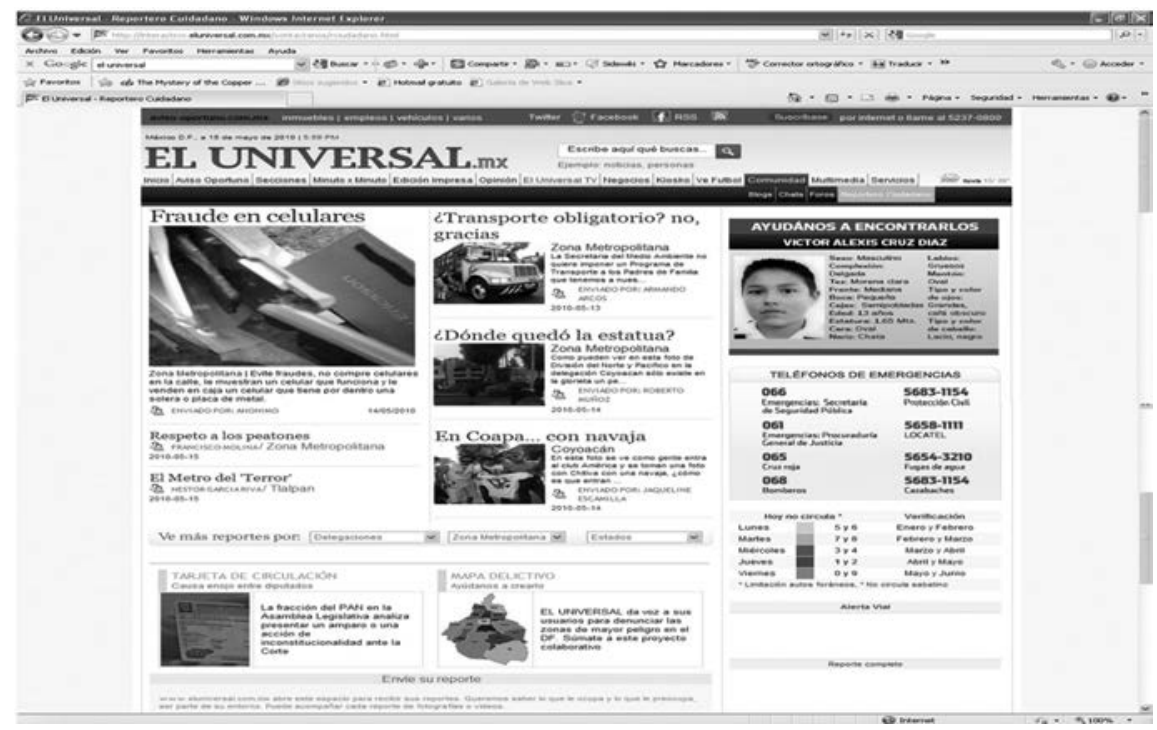


rales, en vez de profundizar en las diferencias, los medios de comunicación cooperen en la búsqueda de soluciones. Es hora de procurar que los dispositivos de información no se limiten a reproducir declaraciones sino a poner en contexto, a buscar nuevas voces de la sociedad, a aplicar buenas prácticas; se requiere un periodismo que comunique, unos medios que busquen la calidad y el rigor, así como ganar en responsabilidad social y estimular la diversidad intercultural.

En definitiva, la comunicación y el periodismo tienen importantes retos que asumir en el marco de la interculturalidad, que consideran la creación de redes especializadas para la detección de distorsiones interculturales, el avance en la utilización de las redes sociales con una perspectiva integradora, la incorporación de prácticas sociales e interculturales en la docencia del periodismo y de la comunicación en colaboración con las organizaciones ciudadanas, como vías para la educación y la solidaridad. Un pensamiento estratégico, no espectacular, para una sociedad intercultural.

\section{Bibliografía}

Association Commercial Television in Europe, ACT (2009). Media $\mathcal{E}$ diversity. How commercial TV channels engage with diversity. <http:// media4diversity.eu/files/annex/ ACT_Good_practices_in_Media_ Diversity_March09.pdf>.
Buckner, Jennie (ed.) (13 de setiembre de 1995). "Batten Symposium". The Charlotte Observer.

Cesida (2006). Guía de estilo. Salud y medios de comunicación. El VIH/Sida. Madrid: Coordinadora Estatal de Vih/Sida y Escola de Sida.

Comisión Europea (2008). "Discriminación en la Unión Europea 2008". Special Eurobarómetro 296. Informe. <http://ec.europa.eu/public_opinion/archives/ebs/ebs_296_en.pdf>. [Consulta: 20 de diciembre del 2009.]

Cytrynblum, Alicia (2004). Periodismo social. Buenos Aires: La Crujía.

Diezhandino, María Pilar (1994). Periodismo de servicio. Barcelona: Bosch.

Echevarría, Javier (2009). "Cultura digital y memoria en red". Arbor Ciencia. Pensamiento y Cultura, CLXXXV 737.

FeAfes (2003). Salud mental y comunicación. Guía de estilo. Madrid: Feafes.

García Canclini, Néstor (2004). Diferentes, desiguales y desconectados. Mapas de la interculturalidad. Barcelona: Gedisa.

Gillmor, Dan (2006). We the media: Grassroots journalism by the people for the people. Cambridge (Massachusetts): O'Reilly Media.

Giridharadas, Anand (25 marzo del 2010). "Humanitarismo 2.0: mapear una crisis". The New York Times-El País. Selección semanal. 
Gorfman, Irving (1986). Estigma. Buenos Aires: Amorrortu Editores.

Grimson, Alejandro (2001). Interculturalidad y comunicación. Bogotá: Norma.

Husband, Charles y Yunis Allan (2002). “Codes of practice and media performance. A systems approach". Tuning into diversity. Inmigrants and ethnic minorities in mass media. Representation and policies. Roma: Fondazione Censis.

InTERnet World Stats (Setiembre del 2009). <http://internetworldstats. com>.

IsRAel Garzón, Estrella (2001-2006). Comunicación y periodismo en una sociedad global. Comunicar la diferencia. México D. F.: Trillas.

—. 2008 "Buenas prácticas para periodistas en el año europeo del diálogo intercultural". Comunicación e Ciudadania 6. <http://www.observatoriodosmedios.org/mediateca/ observatorio/xornadas/200803/artigo19.pdf>.

—. (2010). "Dispositifs de médiation journalistique et interculturalité", en Thiéblemont-Dollet, S. y A. Koukoutsaki-Monnier (dirs.). Médias, dispositifs, médiations. Nancy: Presses Universitaires de Nancy.

Javaloy, Federico (2001). Comportamiento colectivo y movimientos sociales. Madrid: Pearson Educación.
Lange, Yasha (2009). Vivre Ensemble. Conseil de l'Europe: Strasbourg. $<$ http://www.coe.int/t/dghl/standardsetting/media/Doc/livingtogether_fr.pdf $>$.

Morillon, Lucie y Jean-François Julliard (s/f). "Web 2.0 vs control 2.0". <http://www.rsf-es.org/ news/internet-web-2-0-versus-control-2-0/>.

Murciano, Marcial (dir.) (s/f). “La prensa y la cooperación internacional". <http://www.ipsnoticias.net/ documentos/ips_prensa_y_cooperacion.pdf>. [Consulta: 20 de diciembre del 2010.]

PINO, Iván (s/f). <http://www.canalsolidario.org/noticia/comunicacion2-0-esencia-ong-tu-organizacionno-se-ha-puesto-las-pilas/11300>. [Consulta: 20 de mayo del 2010.]

ONU (1948). Declaración Universal de los Derechos Humanos. Artículo 1.

UnESCO (2001). Declaración Universal sobre la Diversidad Cultural. Artículo 4.

Varela, Juan (2005). "Periodismo participativo: el Periodismo 3.0", en Rojas, Octavio I.; Alonso, Julio; Antúnez, José Luis y José Luis Orihuela. Blogs. La conversación en Internet que está revolucionando medios, empresas y a ciudadanos. Madrid: ESIC Editorial. 